LA-UR- 95- $\quad 1439$

Coff-950476--5

Title:

THE DESIGN AND CHARACTERIZATION OF TOROIDAL-SHAPED NOVA HOHLRAUMS THAT SIMULATE NATIONAL IGNITION FACILITY PLASMA CONDITIONS FOR PLASMA INSTABILITY EXPERIMENTS

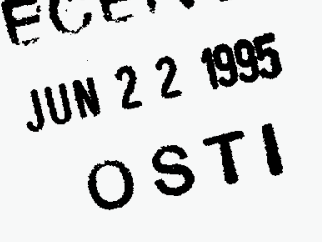

Author(s):

B. H. Wilde $\dagger$, J. C. Fernandez $\dagger$, W. W. Hsing $\dagger$, J. A. Cobble $\dagger$, N. D. Delamatert, B. H. Failor

W. J. Krauser $\dagger$, and E. L. Lindman $\dagger$

† Los Alamos National Laboratory, Los Alamos, NM, 87545

$\ddagger$ Physics International, Los Angeles, CA

Submitted to:

AIP Proceedings of the 12th International Conference on "Laser Interaction and Related Plasma Phenomena", Senri Life Science Center, Osaka, Japan, April 24-28, 1995

S

DISTRIBUTION OF THIS DOCUMENT IS UNLIMTED

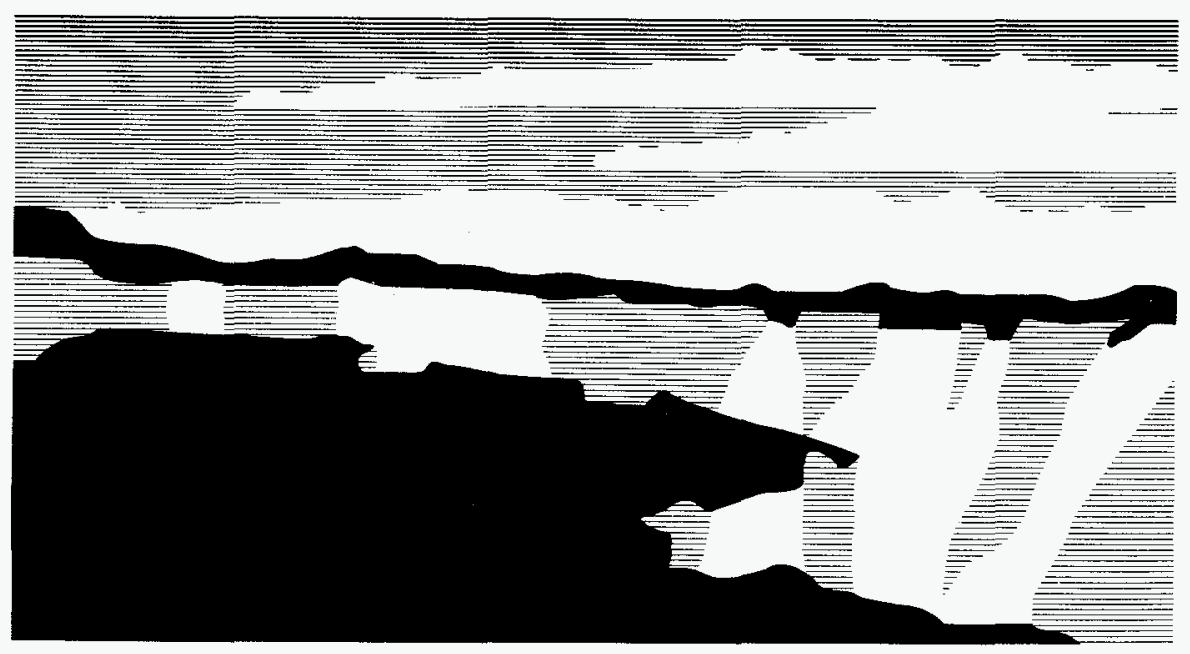

Los Alamos National Laboratory, an affirmative action/equal opportunity emplóyer, is operated by the University of California for the U.S. Department of Energy under contract W-7405-ENG-36. By acceptance of this article, the publisher recognizes that the U.S. Government retains a nonexclusive, royalty-free license to publish or reproduce the published form of this contribution, or to allow others to do so, for U.S. Government purposes. The Los Alamos.National Laboratory requests that the publisher identify this article as work performed under the auspices of the U.S. Department of Ener 


\section{DISCLAIMER}

This report was prepared as an account of work sponsored by an agency of the United States Government. Neither the United States Government nor any agency thereof, nor any of their employees, make any warranty, express or implied, or assumes any legal liability or responsibility for the accuracy, completeness, or usefulness of any information, apparatus, product, or process disclosed, or represents that its use would not infringe privately owned rights. Reference herein to any specific commercial product, process, or service by trade name, trademark, manufacturer, or otherwise does not necessarily constitute or imply its endorsement, recommendation, or favoring by the United States Government or any agency thereof. The views and opinions of authors expressed herein do not necessarily state or reflect those of the United States Government or any agency thereof. 


\section{DISCLAIMER}

Portions of this document may be illegible in electronic image products. Images are produced from the best available original document. 


\title{
The Design and Characterization of Toroidal- shaped NOVA Hohlraums that Simulate National Ignition Facility Plasma Conditions for Plasma Instability Experiments*
}

\author{
B. H. Wilde†, J. C. Fernandez†, W. W. Hsing†, \\ J. A. Cobble†N. D. Delamater†, B. H. Failor $\ddagger$ \\ W. J. Krauser†, and E. L. Lindman $†$ \\ † Los Alamos National Laboratory, Los Alamos, New Mexico 87545 \\ $\ddagger$ Physics International, Los Angeles, CA
}

\begin{abstract}
Special Nova hohlraums have been designed to simulate the plasma conditions calculated for various NIF hohlraum point designs. These hohlraums attempt to maximize the laser pathlength for parametric instability measurements. A toroidal-shaped hohlraum with a diameter of 3200 microns and a length of 1600 microns allows a laser pathlength of about $2 \mathrm{~mm}$. Filling the hohiraum with 1 atmosphere of neopentane gas gives an electron temperature of $3 \mathrm{keV}$ and electron density near 0.1 of critical. Detailed LASNEX calculations for these hohlraums and comparisons to the NIF point design will be presented. Comparisons between data and calculations that characterize the plasma conditions (electron, radiation, and ion temperatures, electron density, etc) in these Nova hohlraums will also be shown.
\end{abstract}

*This work supported under USDOE contract W-7405-ENG-36

\section{INTRODUCTION}

Computer simulations of the indirect-drive point designs for the National Ignition Facility (NIF) using the LASNEX code $(1,2)$ show that the plasma conditions inside of these hohlraums are such that Laser Plasma Instabilities (LPI's) may have a deleterious effects on the performance of the ignition target. In particular, stimulated Brilloiun scattering (SBS) and stimulated Raman scattering (SRS) could scatter a sizeable fraction of the laser energy back out of the target and therefore that energy would not be available for driving the capsule. In addition, unpredictable scattering and absorption inside of the hohlraum would adversely affect capsule implosion symmetry. We have designed a special target for the NOVA laser to investigate LPI's under conditions that approach those expected for the NIF point design. We first describe the plasma conditions in this special toroidal hohlraum design and compare them to the NIF design. Next the

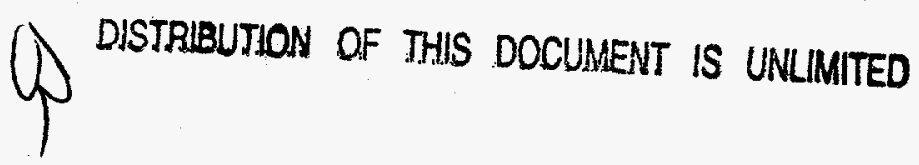


characterization of this hohlraum will be discussed and compared to calculations. The SBS and SRS measurements in this hohlraum are discussed in Refs. 3-6.

\section{TOROIDAL HOHLRAUM DESIGN AND THE NIF}

Figure 1 shows same-scale LASNEX(7) computational meshes and laser rays (at peak power) of the NIF point design, the typical NOVA Scale 1 hohlraum, and our toroidal-shaped hohlraum. The hohlraums are made of gold and are filled with gas to mitigate hohlraum filling and hydrodynamic coupling to the capsule in the NIF. The NIF hohlraum is $5.7 \mathrm{~mm}$ in diameter and $9.6 \mathrm{~mm}$ in length, while the Scale 1 NOVA hohlraum measures $1.6 \mathrm{~mm}$ in diameter and about $2.3 \mathrm{~mm}$ in length. As can be seen from the figure, the latter hohlraum has scale lengths of less than a $\mathrm{mm}$ along the laser path in the gas. To study LPI's it is desirable to have scale lengths approaching those for the NIF target. However, since NOVA's maximum energy is only about $1 / 50$ th that of the NIF (1.8 MJ), actual NIF scale lengths near $10 \%$ of critical density cannot be achieved on NOVA with the required electron temperatures of 3 to $5 \mathrm{keV}$.

The toroidal hohlraum for NOVA is $3.2 \mathrm{~mm}$ in diameter and has a length of 1.6 $\mathrm{mm}$ giving a scale length of about $2 \mathrm{~mm}$. There are 5 NOVA beams on each side with some of them crossing at the central vertical axis of the hohlraum. Normal incidence at the wall is intended to simplify future modeling of the SBS. The laser typically delivers $30 \mathrm{~kJ}$ at $3 \omega$ (351 nm wavelength) in the pulse shape as shown in Fig. 1d. For comparison, Fig. 1d also shows the so called PS22 pulse shape used in the Scale 1 symmetry experiments and the NIF pulse shape for the point design. For the interaction experiments the probe beam would typically have a $1 \mathrm{~ns}$ square pulse delayed a few hundred picoseconds with respect to the main heater beams and with different RPP's (Random Phase Plates) for spatial smoothing, one or four colors, SSD (Smoothing by Spectral Dispersion), f/4.3 or f/8, etc. (3-6). These toroidal hohlraums have been fielded with a $2 \mu \mathrm{m}$ thick $\mathrm{CH}$ liner, $4 \mathrm{mg} / \mathrm{cm}^{3} \mathrm{CH}_{2}$ foam, and with $1 \mathrm{Atm}$ of neopentane $\left(\mathrm{C}_{5} \mathrm{H}_{12}\right)$, deuterated neopentane $\left(\mathrm{C}_{5} \mathrm{D}_{12}\right)$, and carbon dioxide $\left(\mathrm{CO}_{2}\right)$. The gas is contained by placing a $0.25 \mu \mathrm{m}$ thick $\mathrm{Si}_{3} \mathrm{~N}_{4}$ window across the laser entrance holes (LEH'S).

At room temperature 1 Atm of $\mathrm{C}_{5} \mathrm{H}_{12}, \mathrm{C}_{5} \mathrm{D}_{12}$, and $\mathrm{CO}_{2}$ have mass densities of $3,3.4$, and $1.8 \mathrm{mg} / \mathrm{cm}^{3}$ respectively, and when totally ionized give electron densities that are 11,11 , and $6 \%$ of the critical density at $3 \omega\left(9 \times 1021 / \mathrm{cm}^{3}\right)$. Recently, we have also fielded these hohlraums with $5 \mathrm{Atm}$ of $\mathrm{H}$ and $\mathrm{He}-\mathrm{H}(3 \%$ of critical). He-H at $3 \%$ critical is the present gas fill of choice for the NIF point design. However, to approach the near $10 \%$ critical density achieved in the NIF target at peak laser power, we hope to field $10 \mathrm{Atm}$ of $\mathrm{He}-\mathrm{H}$ (at 6\%). Cryogenic liquid nitrogen targets are also being considered to get even higher densities. Since most of the interaction and the plasma characterization experiments were fielded with neopentane, the rest of this paper will concentrate on neopentane. However, Refs. 3-6 discuss LPI measurements for various gases.

Both the NIF and the toroidal hohlraum modelling were done with the same physics using the two-dimensional radiation-hydrodynamics LASNEX code (7). 

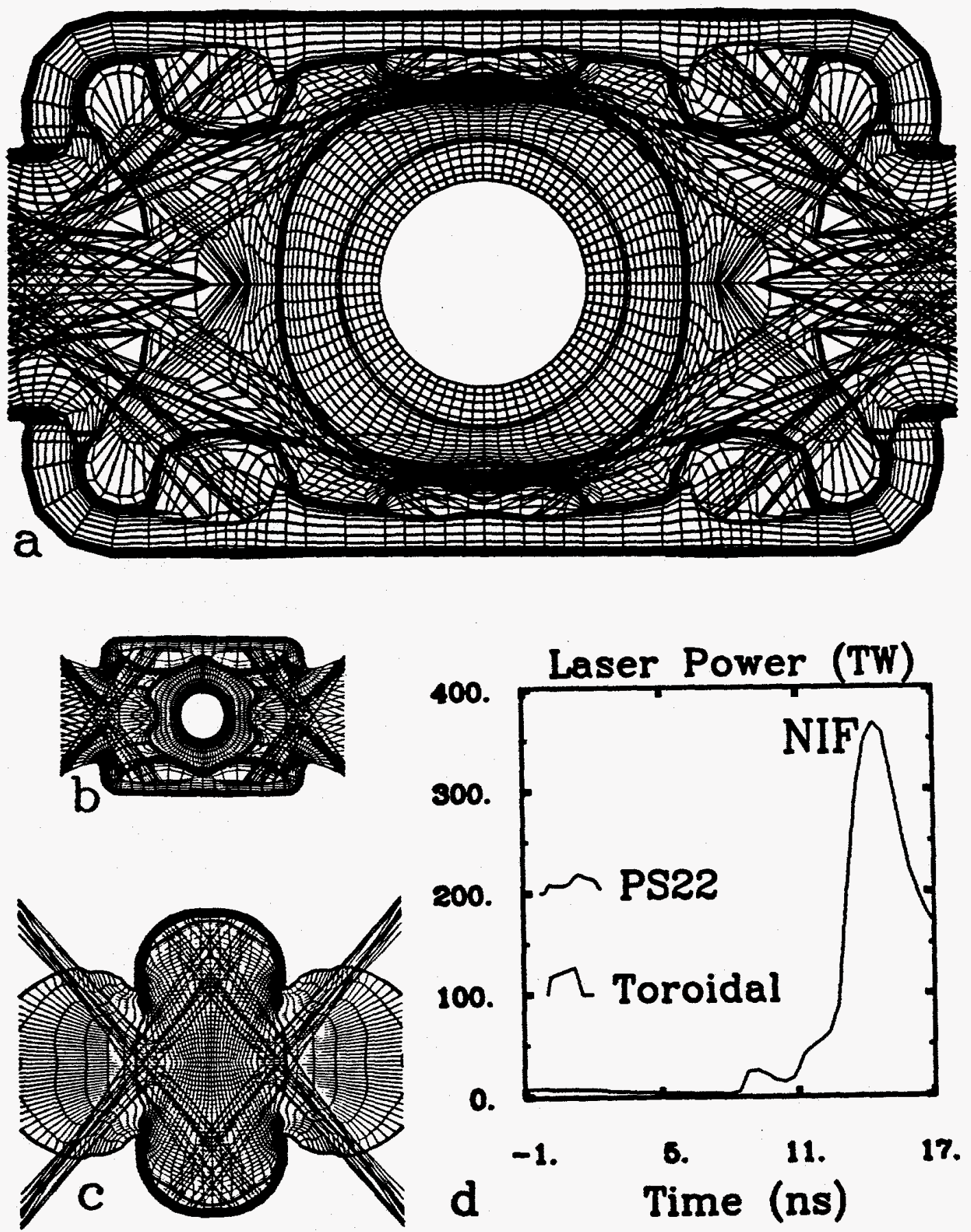

Figure 1. LASNEX meshes and laser rays at peak laser power for a) the NIF $\left(0.03 n_{c} \mathrm{He}-\mathrm{H}\right.$ gas), b) the standard Scale 1 NOVA (PS22 pulse shape, $0.03 n_{c}$ methane gas), and c) the toroidal NOVA hohlraums. The laser power for these 3 hohlraums is shown in d), where the NOVA pulses are offset for clarity. The 3D laser beams are approximated by $2 D$ cones. 


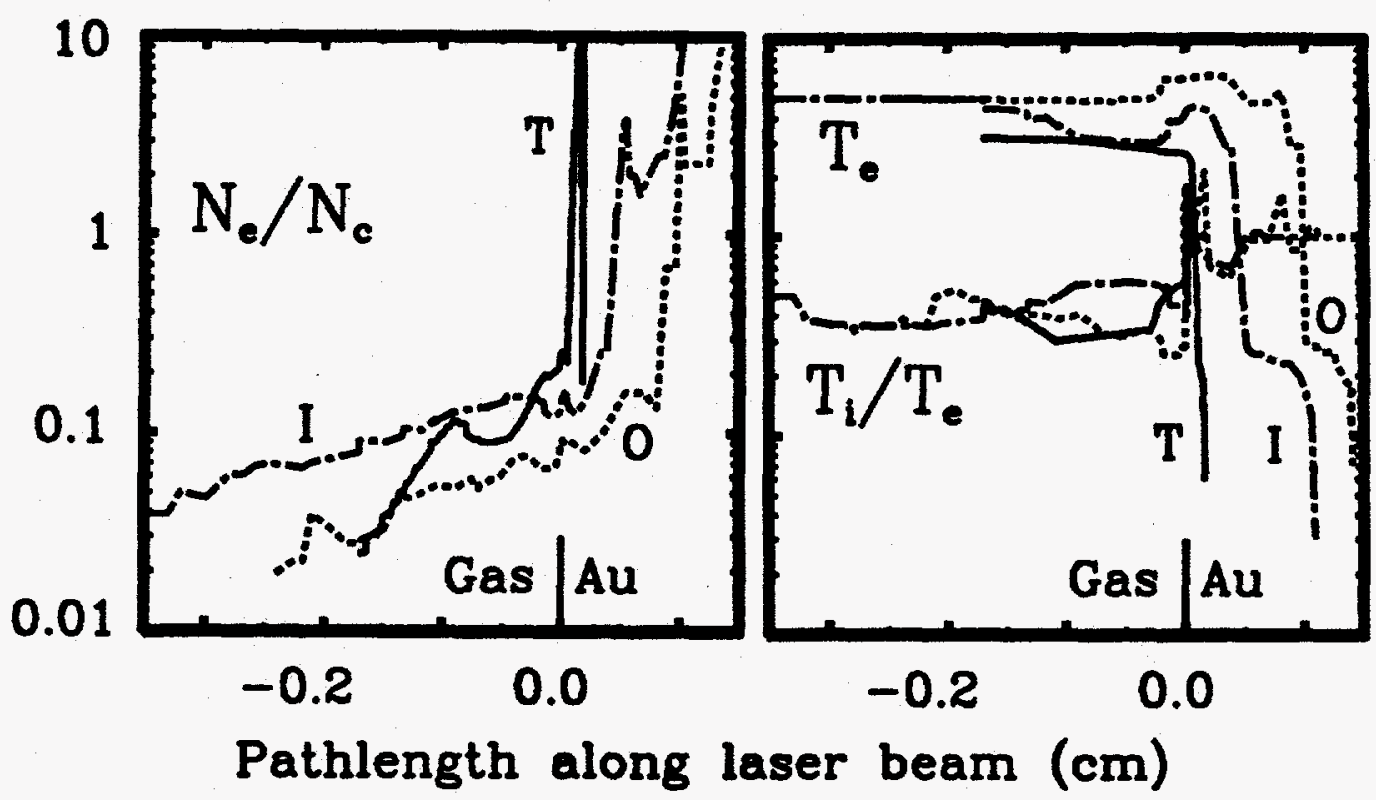

FIGURE 2. LASNEX plasma conditions along the pathlength of the laser beams for the inner ( $\mathrm{I}=\mathrm{dot}$-dash) and outer ( $\mathrm{O}=$ dash) cones of the NIF and the toroidal ( $T=$ solid) hohlraums. Since presumably, the gas is the amplifying medium for LPI's, the curves have been lined up such that the gas-gold interface is at the origin.

To obtain the correct gold conversion efficiency and albedo requires non-LTE (Local Thermodynamic Equilibrium) atomic physics and the best available radiation transport.

Although, the NIF He-H fill starts at 3\% critical, at peak laser power (14.5ns), the gold wall and the $\mathrm{CH}$ capsule ablator have blown off to give near $10 \%$ critical densities in the gas. Figure 2 shows plasma conditions as calculated with LASNEX for both the inner and outer cones of the NIF at peak laser power as a function of distance along the laser path. Figure 2 also shows the same conditions in the NOVA toroidal hohlraum at 1 ns slightly before the peak of the laser pulse used for this hohlraum. The increasing power ramp as shown in Fig. 1d keeps the plasma conditions relatively constant for about $\mathbf{4 0 0}$ picoseconds. In the gas near the gold wall, the toroidal hohlraum has electron temperatures near $3 \mathrm{keV}$, similar to the inner cone of the NIF, but lower than the $5 \mathrm{keV}$ of the outer cone. The electron density in the toroidal hohlraum is near $10 \%$ of critical, between that of the inner and outer cone of the NIF. As expected, the scale length in the gas of the toroidal hohlraum is shorter than in the NIF but more than twice as long as in the Scale 1 gas-filled symmetry NOVA hohlraums. The ratio of ion temperature to electron temperature is the same in the outer cone of the NIF, but is lower than in the inner cone of the NIF. However, this should only help to quench SBS in the inner cone of the NIF compared to the toroidal hohlraum through ion Landau damping (8). The radiation temperature is about $300 \mathrm{eV}$ in the NIF and $200 \mathrm{eV}$ in the toroidal hohlraum and is almost constant along the beam paths. 


\section{PLASMA CHARACTERIZATION}

In order to perform relevant laser plasma instability experiments, it is necessary to confirm the plasma conditions calculated by the LASNEX simulations with experiments. For the toroidal hohlraum we have measured the radiation, electron, and ion temperatures and the electron density, in addition to laser propagation times through the cold gas.

LASNEX calculates that it takes about 100 ps for the laser to burn through the $\mathrm{Si}_{3} \mathrm{~N}_{4}$ windows that are across the LEH's. This is confirmed by temporally and spectrally resolved SBS measurements which show strong SBS signals for about $100 \mathrm{ps}$ when the density of the $\mathrm{Si}_{3} \mathrm{~N}_{4}$ is above $\mathrm{n}_{d} / 10$.

To measure the propagation time of the laser through the cold neopentane gas from the $\mathrm{Si}_{3} \mathrm{~N}_{4}$ window to the gold wall, a $2000 \mathrm{~A}^{\circ}$ thick aluminum patch was used to replace the gold wall where one of the beams would hit the wall. Since the $\mathrm{Z}$ of the $\mathrm{Si}$ and $\mathrm{Al}$ are nearly the same, the stripping times of the two elements are comparable. By viewing the emission of the $\mathrm{Si} \mathrm{He}-\alpha$ line of the $\mathrm{Si}_{3} \mathrm{~N}_{4}$ window and the Al He- $\alpha$ line of the aluminum patch in the same line of sight with a temporally streaked spectrometer, one measures a propagation time to the wall of $360 \mathrm{ps}$ in good agreement with the calculated $350 \mathrm{ps}$.

The radiation temperature is measured through a hole cut in the side of the hohlraum (covered with $0.5 \mu \mathrm{m}$ mylar) looking at the gold wall with the broadband DANTE $x$-ray spectrometer (9). Figure 3 shows the time dependant temperatures deconvolved from the 8 XRD filter-fluorescer channels for three shots with $3 \mathrm{mg} / \mathrm{cm}^{3}$ neopentane gas, normalized to $30 \mathrm{~kJ}$ energy in the laser pulse. After

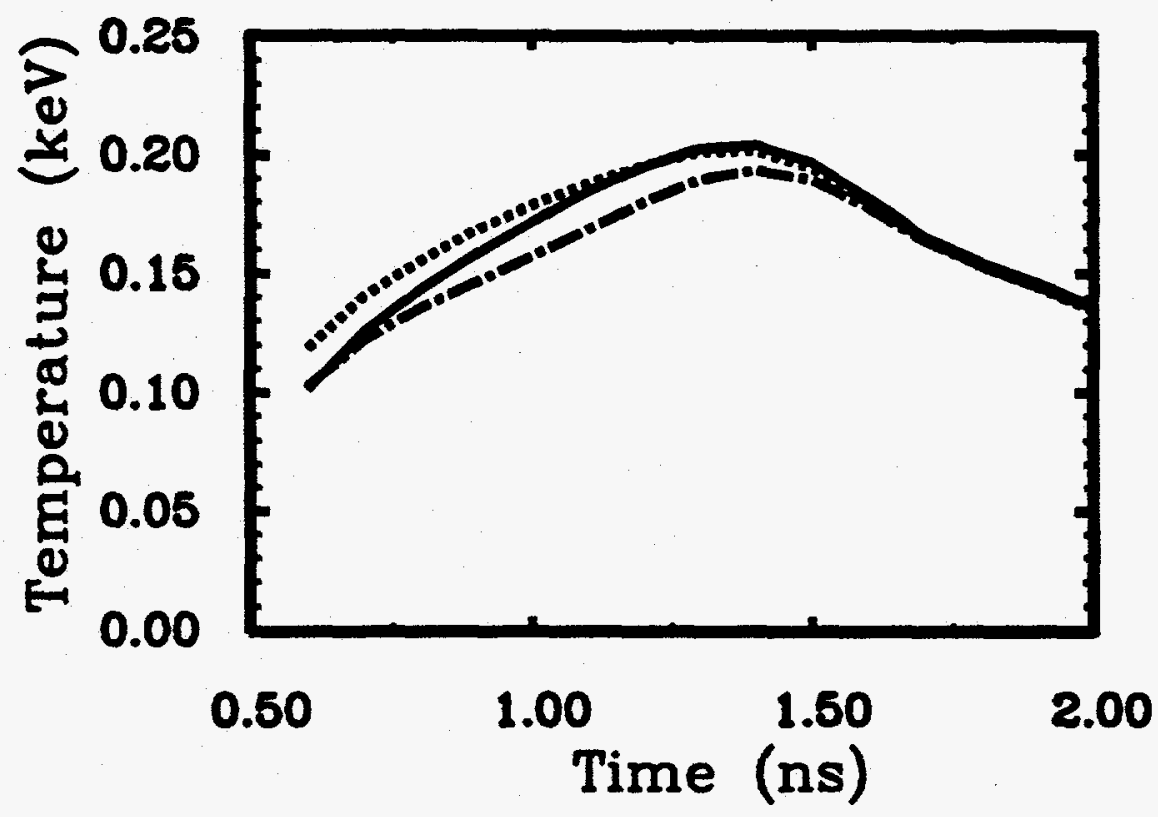

FIGURE 3. DANTE measured radiation temperatures for three almost identical toroidal hohlraums normalized to $30 \mathrm{~kJ}$ laser energy. 
corrections for the gold albedo and the mylar transmission are applied, the LASNEX calculations agree very well with the data, i.e. the peak, rise time and shape of the radiation temperature agree.

To measure the electron temperature, a $\operatorname{Ti} / \mathrm{Cr}(50 / 50)$ coated $\left(2400 \mathrm{~A}^{\circ}\right.$ thick) carbon fiber ( $9 \mu \mathrm{m}$ diameter) is placed approximately at the center of the hohlraum along its vertical axis. The isoelectronic line ratios of the $\mathrm{Ti}$ and $\mathrm{Cr} \mathrm{He}-\alpha$ are a function of the electron temperature (10) and are measured with a time and space resolved spectrometer. The fiber expansion as a function of time is monitored with a time resolved $\mathrm{x}$-ray pinhole camera (WAX) that views the fiber through the laser entrance hole. Since the fiber is positioned in a three dimensional configuration, it can only be approximately modelled with the 2D LASNEX code. Figure $4 \mathrm{a}$ shows a LASNEX interface and mesh plot at $1 \mathrm{~ns}$ with the fiber modelled as a torus in a position that would intercept the laser beams. Models have also been calculated that have the toroidal fiber positioned closer to the axis outside of the laser beams or as a cylindrical fiber on the symmetry axis. Figure $4 \mathrm{~b}$ shows that the fiber expansion is relatively insensitive to these various $2 \mathrm{D}$ approximations to the actual 3D geometry and is in good agreement with the fiber expansion measured by the $x$-ray images. Figure $4 \mathrm{c}$ shows the electron temperature along the fiber from the hohlraum center towards the gold wall as calculated with LASNEX at three times and as measured from the $\mathrm{TI} / \mathrm{Cr}$ line ratios. Since the experimental errors are about $0.5 \mathrm{keV}$, the agreement with calculations is quite good.

By filling the hohlraum with deuterated neopentane $\left(C_{5} D_{12}\right)$, and using the time of flight spreading of the DD generated neutrons, a peak ion temperature of 2 $\mathrm{keV}$ has been inferred, in good agreement with the LASNEX simulation. Even though the peak temperature does not occur until 2 ns, after the LPI measurements are over, this result provides more confidence in our simulations.

Spectrally and temporally resolved SRS measurements indicate the presence of densities near $10 \%$ critical. SDOSS $(5,6)$ measurements also show the presence of $25 \%$ critical density (via two plasmon decay at $3 / 2 \omega) 800 \mu \mathrm{m}$ off axis in the midplane of the hohlraum where the laser beams cross. This disagrees with the LASNEX calculations and is not yet understood.

\section{CONCLUSIONS}

We have designed a hohlraum for NOVA that has plasma conditions that approach those of the NIF point design with electron temperatures of $3 \mathrm{keV}$ and electron densities of $10 \%$ of critical for scale lengths of about $2 \mathrm{~mm}$. These plasma conditions have been verified experimentally and agree well with LASNEX computer simulations. Additional measurements that provide energy balance and laser propagation information also agree with the simulations. Various LPI experiments have been and are being fielded in this toroidal geometry(3-6). 

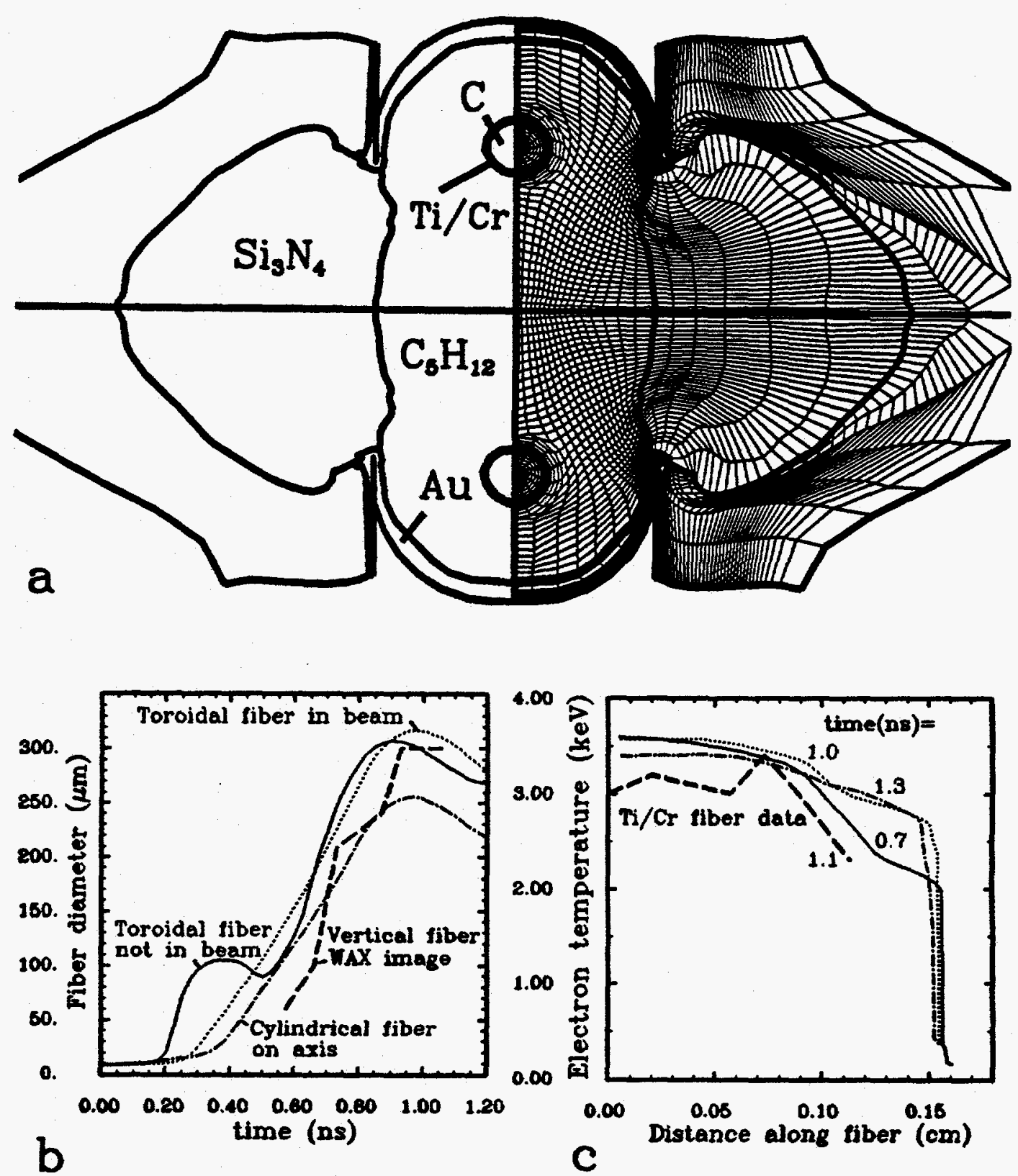

FIGURE 4. LASNEX interface and mesh plots at $1 \mathrm{~ns}$ for a toroidal TVCr coated $\mathrm{C}$ fiber that is placed in the path of the laser beams (a). The fiber expansion as calculated with various $2 \mathrm{D}$ approximations and compared to the $x$-ray image data (b). The measured electron temperature along the vertical fiber compared to the LASNEX calculations (c). 


\section{REFERENCES}

1. W. Haan, S. M. Pollaine, J. D. Lindl, L. J. Suter, R. L. Berger, L. V. Powers, W. E. Alley, P. A. Amendt, J. A. Futterman, W. K. Levedahl, M. D. Rosen, D. P. Rowley, R. . Sacks, A. I. Shestakov, L Strobel, G. L. Tabak, G. S. V. Weber, G. B. Zimmerman, W. J Krauser,D. C. Wilson, D. C. Coggesshall, D. B. Harris, N. M. Hoffman, and B. H. Wilde, "Design and Modeling of Ignition Targets for the National Ignition Facility", invited talk., 12th International Conference on "Laser Interaction and Related Plasma Phenomena", April 1995, paper Tull-1, this conference.

2. W. J. Krauser, B. H. Wilde, D. C. Wilson, P. Bradley, F. Swenson, and R. A. Kopp, "Integrated Ignition Calculations for Indirectly Driven Targets", 12th International Conference on "Laser Interaction and Related Plasma Phenomena", April 1995, paper MoP-1, this conference..

3. J. C. Fernandez, J. A. Cobble, P. L. Gobby, E. L. Lindman, D. S. Montgomery, H. A. Rose, B. H. Wilde, and M. D. Wilke, "Brillouin Backscatter and Seeding Mechanisms in NOVA Hohlraums," 12th International Conference on "Laser Interaction and Related Plasma Phenomena", April 1995, paper TuP-5, this conference..

4. J. C. Fernandez, J. A. Cobble, B. H. Failor, W. W. Hsing, H. A. Rose, B. H. Wilde, K. S. Bradley, P. L. Gobby, H. N. Kornblum, and D. S. Montgomery "Dependence of Stimulated Brillouin Scattering on Laser Intensity, Laser F Number and Ion Species in Hohlraum Plasmas (U)" Submitted to Physical Review Letters, 1995.

5. J. A. Cobble, S. Evans, J. A. Fernandez, J. Oertel, R. Watt, B. H. Wilde, "SDOSS: a Spatially Discriminating, Optical Streaked Spectrograph," 12th International conference on "Laser Interaction and Related Plasma Phenomena", April 1995, paper WdII-3, this conference..

6. J. A. Cobble, J. C. Fernandez, B. H. Wilde, S. Evans, J. Jimerson, J. Oertel, D. S. Montgomery, and C. C. Gomez, "Simultaneous Temporal, Spectral, and Spatial resolution of Laser Scatter from Parametric Plasma Instabilities (U)", Submitted to Review of Scientific Instruments, 1995.

7. G. B. Zimmerman and W. L. Kruer, Comments Plasma Phys. Controlled Fusion 2, 51 (1975).

8. H. X. Vu, J. M. Wallace, and B. Bezzerides, Phys. of Plasmas (1994), submitted.

9. H. N. Kornblum, R. L. Kaufman, and J. A. Smith, Rev. of Sci. Instr. 57, 2179 (1986).

10. R. S. Marjoribanks, M. C. Richardson, P. A. Jaaninagi, and R. Epstein, Phys. Rev A46, 1747, (1992). 